\title{
A comparative case study on clients participation in a 'traditional' and in an agile software company
}

\author{
Zornitza Bakalova, Maya Daneva \\ University of Twente \\ Netherlands \\ Tel.: + $31534894344 /$ +31534892889 \\ \{z.bakalova,m.daneva\}@utwente.nl
}

\begin{abstract}
Agile literature suggests that the active and continuous participation and involvement of the clients throughout the project is key to building the right product and raise users' satisfaction. However, relatively little research has been made on comparing what makes clients happy in 'traditional' companies that use planed-driven processes and in agile companies. In turn, it's hard to collect and evaluate evidence in favor of either settings. This paper fills in this gap and compares two software development companies in a NordEuropean country in respect to client participation and its impact on the clients' satisfaction with the project. One of the companies is agile by its design while the other follows a 'traditional' software development approach. Our study suggests that active clients' participation is not an exclusive attribute of agile projects and that it can be successfully integrated (and implemented) in a 'traditional' project as well. Further, the study shows that by involving clients, software companies have the chance to get higher customer satisfaction, regardless whether or not they implement agile software development processes. Although our study is not quantitative in nature, we think that it is indicative about the impact of the factor "client's participation" on the client's satisfaction.
\end{abstract}

\section{Categories and Subject Descriptors \\ D.2.9 Management}

\section{General Terms}

Management, Human Factors

\section{Keywords}

Customer participation, comparative case study, agile development

\section{INTRODUCTION}

Active and continuous participation and involvement of the clients throughout the project is a key feature of the agile software development and project management philosophy. This philosophy suggests an open software development method in which the suggestions and changes recommended by clients are assimilated smoothly in the development process. Clients are explicitly made responsible for providing information and making business decisions during a project, including prioritization of the requirements according to their value for the client's business. This flexibility allows developers to mould the software application, without putting in any extra efforts and resources, in the direction, intended by the clients. Ambler, a prominent agile practitioner, refers to active stakeholder participation as "An Agile Best Practice" [1].

The agile proponents and practitioners claim [2] that this leads to higher customer satisfaction, to creating value fast and early in the project, and to building the product that the client really wants. In the agile software engineering (SE) literature, a number of aspects of clients participation in agile context has been studied, for example the three C's (coordination, collaboration and communication), the role of the on-site customer, the challenges related to customers' involvement, and communication challenges [4]. However, Sharp and Robinson [3] who study agile teams for a decade, point out that the specific mechanisms used to support the clientparticipation-related activities seem more difficult to pin down. To the best of our knowledge, there are no studies that have compared the levels of clients' involvement in traditional and in agile projects. In this research we want to gain deeper understanding about the phenomenon of the customer's participation and its implications for software projects in both settings. We think that if a company is aware of the possible effects that the active client participation has, for example, on the client satisfaction in a software project, the company can deliberately use this knowledge to enhance their collaborative interactions with their clients, and ultimately, improve their chances for business success because the more their clients are and the happier the clients are, the more sustainable the company's business position in the software market place. (RQ):

We are set out to answer the following research questions

RQ1: What are the differences and similarities between agile and non-agile projects in respect to client's participation?

RQ2: In which way do the clients get actively involved during a non-agile real-life project and what are the implications of this involvement for the project in terms of client satisfaction?

To answer these questions, we adopted a qualitative case study research method [5]. The rest of the paper is structured as 
follows: in section 2 we provide background and motivate this research. Section 3 provides summary of published work on client participation in software engineering. Section 4 provides background on the case study, section 5 describes the results in respect to the research topic. In section 6 we discuss the results, section 7 covers the limitations of study and section 8 concludes the paper and provides an outlook for future research.

\section{BACKGROUND AND MOTIVATION}

In the recent years, SE authors that carried out studies on the clients' participation in software development, have focused predominantly on the empirical context of agile software organizations. As part of this research, we searched the Scopus database for empirical studies on the user involvement in SE and we found very few studies published in the last five years $(2005-2010)$ that address the client participation - and its relationship to project success and to client satisfaction, in plan-driven context.

In those studies that focused on plan-driven contexts (and were published between 2005 and 2010), we found that the authors of the respective studies were not SE scholars, but researchers from the field of Human Media Interaction (e.g. [6]), Social Science and Management Science (e.g. [7,8]), and Information Systems Research (e.g. [9]). Moreover, we also noticed that while the studies on agile client participation (dated in the same period, 2005-2010) are more explorative in nature (for example, [4]) and are mostly devoted to the analysis of the mechanisms through which client-developer collaboration happens, the empirical studies that include plandriven projects (e.g. $[6,7,8,9])$ treat other aspects of clientdeveloper collaboration and rarely discuss explicitly the mechanisms that make or break it. Moreover, these studies use for their purposes a number of theories from the authors' respective fields, e.g. Management Sciences. While the observations we presented in this paragraph are not surprising, they make us think that it seems to be challenging for SE researchers to clearly see whether the agile practitioners' claim that client participation leads to project success is attributable solely to the use of the agile philosophy or to other factors.

Furthermore, when we looked into the papers authored by members of the scientific agile-SE community $[3,4,11,12$, $13,14,15]$ we noticed that these authors have paid much attention to studying the role of the agile customer in XP, the most prominent agile methodology, as it prescribes explicitly the way the of customer's involvement throughout the project. According to the XP methodologists $[1,10]$ this should be implemented through the availability of so-called on-site customer. In those organizations who reportedly used XP, the practice of 'on-site customer' may take many forms ranging from 'on-the-phone customer' to 'developer on-the-client-site', and these forms have been investigated in a number of studies. For example, [11] discusses various important challenges related to the implementation of the 'on-site customer' practice. Further, the problem of the customer involvement has been investigated and discussed by a number of authors $[4,12$, 13]. Other aspects of the user involvement that have attracted the attention of the researchers are communication challenges [14], challenges in the global and distributed development [15], and trust [3].

The fact that client participation was deemed important by both agile and non-agile SE authors as well as by authors from other fields, motivated us in investigating the specific ways that companies are using in their daily practice to enhance client-developer collaboration. Moreover, our work was motivated by the observations in our review of the literature sources in this section (1) that there is little evidence from case studies that compare how agile and plan-driven processes achieve clients participation and what the relationships are among client participation, project success and client satisfaction, and (2) that whatever evidence is published in agile SE literature, it mostly refers to XP. We found it intriguing to sample projects in companies and make explicit the knowledge of professionals in both agile and plan-driven projects regarding the active participation of their clients in the software process and about the possible relationships that might exist among clients participation, projects success and client satisfaction.

Last, we also make the note that in our search, we found only one comparative study [16] of plan-driven (that is, waterfall) and agile approaches that investigated the topic of project success. The authors of this study (i) acknowledge that the research area of "success in SE projects still lacks a holistic model capable to explain project success comprehensively", (ii) explore the anticipation signals of project success of Scrum and waterfall projects and (iii) call to encourage the research community to pursue the development of a holistic model. Our research effort directly responds to this call and aims at providing some empirical evidence that could possibly be used to inform the planning of follow-up research on project success (and its relation to client participation).

\section{HistoricAl ROUTES OF THE IDEA OF Client Participation}

This section elucidates the notion of client participation in software/system development projects based on previously published research in other research fields. Whereas the active role of the client is explicitly stated in the agile SE literature and - as Abbas et all indicate [17], the idea of daily communication and on-site customer is new and specific to agile, we note that before the 'agile era' the importance of clients' collaboration was stressed in the fields of 'collaborative systems modeling' [18], 'participatory design' [19], 'user-centered design' [20]. In [18] the relationship between specific participative behaviors and user satisfaction was examined in situations where the need for participation was high. The authors of this study compared their results with results in situations characterized with a lower need for participation. The authors found that not all participative behaviors were equally effective in all situations. The conclusion was that the effectiveness of a participative behavior is contingent on the level of task complexity and on the level of system complexity. Furthermore, [9] compares participatory design with the XP practices of client involvement and [20] advocates to integrate user-centered concerns (from the Human-Computer Interaction field) in XP projects. These researchers [20] also present the results of a study on customer collaboration in practice, however in this study only agile and XP practitioners were involved. Sharp and Robinson [20] provide a summary of focus-group discussions on 'on-site customer', where the participants explored, shared and reflected on their practical experiences of making customer collaboration work in all its various forms. The discussion covered the following issues: (i) trust, 
(ii) the bridge (between the two worlds, and modeling as a possible bridge); (iii) access to customers; (iv) workshops; (v) supporting collaboration.

Furthermore, Doll and Deng [21] report on an investigation of the relationship between user participation and user satisfaction. They reach the conclusion that only participation in the analysis of the client's information needs can indeed predict end-user satisfaction and task productivity.

Our research was informed by the published results of the authors that we included in Sections 2 and 3. Knowing those notions of client participation that were subjected to research in the past increased our theoretical sensitivity [5] and helped us think of specific interview questions that we could possibly use in the pursuit of answers to our research questions.

\section{The Case Study Process}

In order to answer our RQs we performed a qualitative case study following the guidelines of R. Yin [14]. Our case study research is exploratory in nature. We do not use any previously published theoretical model as a basis for our study. However, as Yin suggests, we informed our case study protocol by a review of related literature (as already presented in Sections 2 and 3). We executed the case study by carrying out the following steps:

(1) Formulate open-ended questions for in-depth narrative interviews;

(2) Cary out the interviews with representatives of two software companies;

(3) Compare the interview data;

(4) Write-up the findings.

Our study includes two Nord-European companies. The first one is a relatively young company (it has been in business for a decade). It has been designed by its founders as an agile organization. The second company has a longer business history and identifies itself as a plan-driven organization. The companies are not competitors. They serve two different markets and deliver different types of products. Because of confidentiality constraints, here we refer to them as to Company A (the agile company), and Company N (the nonagile company).

\subsection{The execution of the case study process}

Our research plan was executed as follows: First, during a common meeting, representatives of the two companies gave 50 minute presentations on the process that is in place in their company, and on the development method used. In the next step, the researchers interviewed the company representatives in separate interviews that lasted about 60 minute each. Company A participated in the study with two representatives:

- a developer and project manager (because of the flat team structure in the company one person serves multiple roles), and

- another developer, who is responsible as well for governance issues.

The representatives of company $\mathrm{N}$ were the lead architect and technical manager responsible for the delivery of a number of projects.
During the interviews, we discussed questions related to client's involvement and its impact on: (i) building the right product, and (ii) customer satisfaction. Those were unstructured, informal, open and narrative interviews [22]. This form of interviews was chosen because we had a concrete, narrow research goal and wanted to obtain as deep insight as possible. The qualitative research methodologists [23] deem the form of narrative interviews particularly useful for exploring a topic intensively and from the participants' points of view. In our unstructured interviews, we did have some guiding questions and core concepts to ask about, however we did not have a fixed interview protocol and we took the freedom to move the conversation in any direction of interest that might come up. The questions that the researchers asked originated and were triggered by the information provided in the presentations. The conversations emerged from the immediate context defined by the participants. The merit of this interviewing approach is that it lets us carry out highly individualized, contextualized interviews that are also relevant to the practitioners, and not just to us the researchers.

Our interviews included narrative-pointed questions that both (i) covered a longer period of time (e.g. a series of projects delivered for client companies in a specific business sector) and (ii) focused on specific events (e.g. a project initiation for a particular client organization). For example, when studying how developers learn to "talk the client's business language" we asked the practitioners to give us examples of their developers' history as employees in Company N. This question covered the whole period of time in the carrier of our interviewees that they were working in a role interacting with clients. We also included questions pointing to specific events, for example "What happened in the early project stage, when you noticed that one workshop with your clients is not enough for understanding completely the requirements?".

The collected narratives were analyzed by means of thematic analysis techniques [22]. We chose thematic analysis because of the flexibility it offers to researchers. Its use meant the examination of our narrative material for themes (working across the interviews with each company's representatives) and then develop thematic clusters to integrate the themes. Our thematic analysis helped reduce the text units progressively in two rounds. In the first round, we paraphrased whole pieces of text (paragraphs) into summary sentences. In the second round, the sentences were further paraphrased into a few key codes. As indicated in [22], these two reductions "operated" with generalization and condensation of meaning.

\subsection{Description of company $A$}

The company has about 260 employees, divided in departments of approximately 25 people. Each department is specialized in a concrete application domain that the company provides software development services to. For example, the Financial Markets domain, Health Care, and Education. The company is strongly oriented towards providing software as a service. Because of the specialization in concrete domains the company can reuse core parts of the software applications, and extend them with custom-made components in order to tailor the product to the concrete client's needs. The development process of the company is agile, both as process and as company's philosophy. Although the company does not follow a concrete agile method with all its practices, the development process is designed to include the core agile 
characteristics: short iterations and frequent releases, active customer participation, fast reaction to / and accommodation of/ changes.

The company organized its communication with the client by using a wide range of possible practices that can be arranged in a different way depending on the social context of a specific project. In some projects, the idea of 'developer on site' is practiced, which means that the developer, responsible for communication with the clients, can freely access the client's premises and collect the information that he/she needs. In other projects, the communication runs over the phone and the clients can call any time during the regular work hours and express their desires, opinions or concerns. In addition to these options, in some projects a dedicated web site is set up where the clients can track the progress of the project and thus see the timeline for implementing the requirements. This is a form of e-collaboration that aims at reducing the pressure on the developers that comes out of phone calls asking "When will be my feature implemented?" Moreover, e-collaboration is deemed to increase the trust between the parties as the client got the feeling that the developers are really taking him/her seriously, are acting on his/her needs, and that the project is really progressing.

\subsection{Description of the Company $N$}

The company has about 160 employees. Half of them are directly involved in software development. The company has middle-sized projects (4.000 to 15.000 person hours approximately). Each project involved between 5 and 30 people. The majority of the projects (around 75\%) are maintenance projects, i.e. making changes to existing products. The remaining $25 \%$ of the company's projects are new development ones. In contrast to company A, the products of the company $\mathrm{N}$ are intellectual property of the clients and no software components can be reused. The new development is done from scratch. The contractual basis for the projects is 'fixed-price, fixed schedule'. The development phase is preceded by a workshop phase that consists of extensive discussions and meetings with as many clients' representatives as possible. During the so-called 'workshop phase', the following issues are discussed and elucidated:

(1) business case,

(2) functional requirements,

(3) architecture infrastructure,

(4) project management,

(5) maintenance,

(6) security,

(7) usability,

(8) domain knowledge,

(9) test approach.

The workshop phase finishes by providing a quotation for the project. The results on each of the discussed issues are captured in a deliverable. In rare cases where no reliable estimation can be elaborated based on the input during the workshop, this phase can be repeated until more detailed information is collected or some prototyping is done in order to capture the client's needs. The clients' participation during the project consists of weekly sessions. They are included in the contract between the parties as an inseparable part of the project. During the sessions issues are discussed that have been captured in Requests for Information (the so-called RfIs) between the sessions. These RfIs are written by the developers and become part of the project's documentation. According to the company's representative that we interviewed, frequent releases would not work for the majority of the projects the company currently runs. For example it is not feasible and desirable to update frequently a banking software that serves multiple branches of a bank, as this would cause disturbance of the work of the client and possible irritation. Other products that the company $\mathrm{N}$ develops could not be put into production unless the whole functionality is fully developed (e.g. a ticketing system for a big organization). This explains the choice of the development method that the company uses.

In order to better understand the clients' domain, company $\mathrm{N}$ invests in the education of their own staff-members in the business of their clients. Staff that will be included on development teams that deliver systems in a specific business sector go to a specialized training program that let them learn the way businesses in a specific sector operate. This gives the staff members exposure to both the operational procedures common for organizations in a sector and the IT issues related to the support of these operations. The training costs are absorbed by company $\mathrm{N}$, and hence are free of charge for the clients. This way the company wants to make sure that in addition to the excellent expertise in the domain of software development, a good understanding of the client's domain is ensured. In spite of this, it is expected that the client is the one that has to provide the ultimate competence in his/her domain.

\section{Comparing the Processes Involving Client Participation}

We compared the processes of the two companies in two respects. First, we compare the overall processes according to the core agile characteristics as stated in the Agile Manifesto [3]. Second, we narrow down the focus on comparing the specific practices and mechanisms at the two companies related to client participation.

Table 1. compares the processes of the two companies in respect to the practices used. The first column in the table presents the areas explicitly discussed by the Agile Manifesto. In the last two columns of Table 1, we make a decomposition of the development method used in the two companies in respect to these process areas.

We use the areas of the Agile Manifesto as the basis for our comparison, because these areas are deemed the main differences between agile and non-agile development [10]. They are: (i) directly impacted by the level of client's participation, and (ii) are immediately linked to the project's outcome /success/ client's satisfaction. The last two columns in Table 1 explicate the similarities and the differences between the processes of the two companies.

When comparing the columns of the table we observe that both companies differ significantly in respect to:

- the cycles in which the development process is organized,

- the planning (up-front vs. iterative),

- how the product is developed - incrementally vs. in big releases,

- the amount of documentation,

- the response to changes. 
Table 1. Comparison of the processes at Company A and company N.

\begin{tabular}{|c|c|c|}
\hline $\begin{array}{l}\text { Area in the Agile } \\
\text { Manifesto [3] }\end{array}$ & Company A & Company $\mathbf{N}$ \\
\hline $\begin{array}{l}\text { Short iterations } \\
\text { and frequent } \\
\text { releases }\end{array}$ & $\begin{array}{l}\text { - } \quad \text { Defines 'release' as stated in agile literature } \\
\text { [10] (e.g. 2-3 weeks long). } \\
\text { - } \quad \text { Fully complies with these practices. }\end{array}$ & $\begin{array}{l}\text { - Defines release as 'big release'; does not use the } \\
\text { term 'release' as in the agile literature. } \\
\text { - Does not apply the practices of short iterations and } \\
\text { frequent releases; } \\
\text { - Has big releases with detailed planning up-front. }\end{array}$ \\
\hline $\begin{array}{l}\text { Working software } \\
\text { vs. detailed } \\
\text { documentation }\end{array}$ & $\begin{array}{l}\text { Complies with this practice, while the level of } \\
\text { documentation is chosen to comply with the } \\
\text { maturity standards that the company respects. }\end{array}$ & $\begin{array}{c}\text { Both working software and documentation are deemed } \\
\text { equally important and considered critical to project } \\
\text { success. }\end{array}$ \\
\hline $\begin{array}{l}\text { Response to } \\
\text { changes }\end{array}$ & $\begin{array}{l}\text { Changes are handled in three ways: } \\
\text { - } \quad \text { through agile change management in the } \\
\text { product backlog. } \\
\text { - } \text { informally, when changes of a requirement } \\
\text { happens, or } \\
\text { - through a Change Request (CR) when } \\
\text { 'bigger' changes are required that lead to } \\
\text { changes in the schedule/ budget. }\end{array}$ & Handled through CRs) exclusively. \\
\hline $\begin{array}{l}\text { Collaboration and } \\
\text { communication } \\
\text { between clients } \\
\text { and developers. }\end{array}$ & $\begin{array}{l}\text { - Frequent meetings and on an ad-hoc basis, } \\
\text { - Developer on client's site. }\end{array}$ & $\begin{array}{l}\text { - Frequent meetings and on scheduled basis } \\
\text { exclusively } \\
\text { - Workshop at the start of the project, } \\
\text { - Follow-up workshops during weekly sessions, } \\
\text { scheduled according to a plan. }\end{array}$ \\
\hline
\end{tabular}

While company A follows an agile approach in all these areas, company $\mathrm{N}$ sticks with plan-driven (or the so-called 'traditional') practices. Still, the comparison found that in respect to clients' involvement there are significant similarities between the two companies, especially when the amount of clients' cooperation is considered.

Company A used the agile methodology to compartmentalize the entire new software development project into minor stages, each one of them given a specific completion time and specific time slots when the clients interfere. Company N's process is plan-driven process by its design, yet heavily relies on clients' active involvement (through workshops, as we will see in Section 5). However, both companies deemed the work time they spent in interaction with their customers negate the project risks and ensures that the project is completed within stipulated time.

Next, we found that the company $\mathrm{N}$ referred to the following concepts while describing the ways in which they were taking care of their client's active involvement:

- Trust-building - this was ensured by (i) listening to the clients, (ii) studying client's domain, and last but not least (iii) by mutual social events.

- Sharing a common vocabulary - this was implemented by the professional education program that the company provides for part of its employees in order to study the client's area.

- Access to customers - this is defined in the contract and access to information is guaranteed by RfIs. We make the note here that in our earlier case studies $[24,25]$, we investigated a number of agile small companies and we found that a large number of agile projects, especially in the small companies, do not implement the practice of 'client on-site'.
- Workshops - extensive meetings with as many as possible customer representatives as possible; more than one workshop can be organized in case the requirements or the estimates are not clear enough.

We make note that in this section we discuss only the clientvendor collaboration in company $\mathrm{N}$, as company $\mathrm{A}$ is agile by its nature and philosophy and active collaboration with the client is intrinsic to its process, as seen in Section 4.2.

\section{DISCUSSION}

Beck [4] says that there is no process that fits every project, but rather the practices should be tailored to suit the needs of individual projects. Our study suggests that in reality the difference between traditional and agile development can be quite blurred and successful projects can choose their set of practices that best suit the concrete project realms independently from the 'extent of agility' the concrete practice. In the case of this study a traditional company has adopted a very 'agile' practice that shows its merits in completely non-agile project settings. This shows that the practice 'active user participation' can be successfully implemented and incorporated in a context of plan-driven process and big releases. The company has found a way of how to implement this practice to fit the rigor of the more traditional and heavily-documented way of development of company $\mathrm{N}$. This was ensured by a set of mechanisms during different project phases. For example, at the beginning of project these are the workshops with the client, while during the whole project RfIs are used. Moreover, mutual social events with the client's organization are organized once per month for some of the projects. The purpose of all these activities is not only to deliver the right product, but also to promote a spirit of trust and cooperation. As one interviewee put it "That is the personal touch". 
Furthermore, company $\mathrm{N}$ does not experience the problem of not having enough information for the creation of the right product. The results of the study suggest that the context of each particular project might play the essential role for the instantiation of the process. For example, the company $\mathrm{N}$ did not feel it necessary to organize the development in shorter iteration and to deliver the product in multiple releases. On the contrary, according to the representative of the company, this would be counter-productive for the majority of their projects, as the findings of the study of the products require delivering the complete and thoroughly tested functionality as one piece.

When reflecting on our findings that refer to RQ 2 ("In which way do the clients get actively involved during a nonagile real-life project?), we made the observation that the concepts used by our interviewees in their project experiences while referring to client's participation, were similar to those discussed in the study of Sharp and Robinson about client participation in agile [20]. We found that four out of the five concepts formulated by these authors map directly onto our four concepts in Section 5. These four concepts are (i) trust, (ii) the bridge (between the two worlds - and sharing a common vocabulary is a possible bridge); (iii) access to customers; and (iv) workshops. This observation made us consider drawing an interesting conclusion: that regardless whether a company is agile by design or plan-driven by design, the experiences of the company's employees in clients' participation are describable by using the same concepts. This sounds common sense and intuitive, (indeed Sharp and Robinson deem these concepts focal points of any reasoning on clients' involvement), we felt motivated to replicate the study and investigate if this is indeed the case in other setting and also whether or not there are more concepts to add to the list. We make the note that our study did not overlap completely with the 'supporting collaboration' concept in the paper of Sharp and Robinson [20]. We found that the meaning that these authors assigned to this concept differed from the meaning that our interviewees had. We acknowledge that future research is necessary to explore in more depth the variations of meanings that the concept 'collaboration' might have in agile and in non-agile companies.

\section{Limitations OF THE STUDY}

We considered the possible threats to validity [5] of our results. The major limitation of our research setup is that it is focused on two organizations, which restricts the extent to which generalizations can be drawn from its outcomes. This limitation is off-set by the opportunity to gain a deeper understanding of the association between client participation practices and satisfaction of the clients at the end of the projects in which the clients participated.

We also acknowledge the inherent weakness of in-depth narrative interviewing techniques that they are driven by the researcher, meaning that there is always a residual threat to the accuracy of what the case study participants say. However, we believe that in our study, this threat was reduced, because the two authors were present at the conversations.

Last, a common weakness of narrative interviews is that the participants make assumptions about what we, the researchers, want to hear and what we had probably known from our own research experience (regarding the topics discussed). Jovlovich and Bauer [22] warn that interviewees generally assume that the researcher knows something about their project and business realities and that, therefore, they do not talk about all they know because they take it for granted. It might be, therefore, well possible that important aspects of the relationship between project success and client participation and client satisfaction remained unaddressed. We think, however, that this threat is reduced because we have been working with the participants' companies for more than four years in an industry-university research project, and have been meeting them on semi-annual basis to report our results. The meetings gave us the occasions to discuss our findings and ensure that what they meant was understood by the researchers.

\section{Conclusions}

Active customer participation is an essential component of each agile SD methodology. Our purpose in this study is to share with the community the simple mechanisms that one non-agile company has adopted to cover important aspects of client participation that, according to the company, were leading to high customer satisfaction and "building the right product in non-agile project settings" (as one representative put it). We presented a comparative study of the development process of an agile and a non-agile company in respect to: (i) clients' involvement, (ii) frequency of releases, (iii) response to changes. We observed that the non-agile company has successfully implemented mechanisms for active clients' participation during the project. This increases the satisfaction, enhances the level of trust between the parties, creates a feeling of 'personal touch'. We observed these effects both in the traditional and in the agile projects and our study suggests that these effects are a result of the close cooperation and frequent contact with the clients. Further, the study shows that there might not be a clear-cut border between agile and non-agile projects in respect to the practice of clients' involvement and that active customer collaboration throughout the project can be successfully implemented in non-agile projects as well.

We consider our study and its results a first step only and we are conscious about the value of replication studies that would help accumulating more evidence. Our immediate future research plans include carrying out follow up studies in which our goal is to increase the understanding of the underlying mechanisms $[27,28]$ that explain the relationship between project success and client participation.

\section{ACKNOWLEDGMENTS}

We are indebted to all case study participants for sharing their experience and thoughts with us. This study was supported by the Netherlands Organization for Scientific Research (NWO) under the Quadread research project.

\section{REFERENCES}

[1] Ambler, S., Agile modeling, http://www.agilemodeling.com/essays/ activeStakeholderParticipation.htm

[2] Koskela J, P. Abrahamsson, On-Site Customer in an XP Project: Empirical Results from a Case Study, In Software Process Improvement, 2004, Springer Berlin, pp.1-11

[3] Sharp, H., H. Robinson, Three 'C's of agile practice: collaboration, co-ordination and communication, Collaborative Software Engineering, 2010, pp.93-108. 
[4] Martin A, Biddle R., Noble, J: XP Customer Practices: A Grounded Theory. AGILE 2009: pp 33-40

[5] Yin, R. Case Study Research, Sage, 2008.

[6] Iivari, N.,'Representing the User' in software development - a cultural analysis of usability work in the product development context, Journal of Interacting with Computers, 18(4), July 2006, pp. 635-664

[7] Shim, J.T., T. S. Sheu, H.-G. Chen, J. J. Jiang, G. Klein, Coproduction in successful software development projects, Information and Software Technology, 52(10), 2010, pp. 1062-1068

[8] Chen C.-Y. Managing projects from a client perspective: The concept of the meetings-flow approach International Journal of Project Management, August, 2010.

[9] Mattia, A.; Weistroffer, H.R., Information System Development: A Categorical Analysis of User Participation Approaches, Proceedings of the 41st Annual Hawaii International Conference on System Sciences, 2008 , pp. 452

[10] Beck, K. eXtreme Programming Explained: Embrace Change, Addison Wesley, 2000.

[11] Mohammadi, S. Bahman Nikkhahan. Sahar Sohrabi. Challenges of user Involvement in Extreme Programming projects. International Journal of Software Engineering and Its Applications Vol. 3, No. 1, January, 2009

[12] Abrahamsson, P., J. Warsta, M. T. Siponen, J. Ronkainen: New Directions in Agile Methods: A Comparative Analysis. ICSE 2003: pp 244-254

[13] Hoda, R. J. Noble, S. Marshall Agile Undercover: When Customers Don't Collaborate, XP 2010.

[14] Korkala, M., M. Pikkarainen, K. Conboy, Distributed Agile Development: A Case Study of Customer Communication Challenges, in Agile Processes in Software Engineering and Extreme Programming, Springer, 2009

[15] Akbar, R. M. Haris, M.Naeem, Agile framework for globally distributed development environment (the DAD model), in Recent Advances In Computer Engineering, 8th conference on Applied informatics and communications, Greece, 2008

[16] Ikonen, M. P. Abrahamsson, Anticipating Success of a Business-Critical Software Project: A Comparative Case Study of Waterfall and Agile Approaches. ICSOB 2010: 187-192
[17] Abbas, N., A. M. Gravell, G. B. Wills: Historical Roots of Agile Methods: Where Did "Agile Thinking" Come From?. XP 2008: 94-103

[18] McKeen J.D., T. Guimaraes, Successful strategies for user participation in systems development, Journal of Management Information Systems, 14(2), 1997, pp: 133 150.

[19] Rittenbruch, M., G. McEwan, N. Ward, T. Mansfield, D. Bartenstein, Extreme Participation - Moving Extreme Programming Towards Participatory Design, PDC 2002, Proceedings of the Participatory Design Conference, Sweden.

[20] Sharp H, H. Robinson, J. Segal, Integrating User-Centred Design and Software Engineering: A Role for Extreme Programming? BCS-HCI Group's 7th Educators Workshop: Effective Teaching and Training in HCI, 1-2 April 2004

[21] Doll, W., X Deng The collaborative use of information technology: End-user participation and system success, In: Collaborative information technologies, 2002

[22] Jovchelovitch, Sandra; Bauer, Martin W. (2000). Narrative interviewing in Bauer, Martin W.; Gaskell, G.; Eds., Qualitative researching with text, image and sound : a practical handbook. London, England: SAGE Publications, 2000.

[23] Fontana,A., Frey, J, The interview: from structured questions to negotiated text. In N.K. Denzin, Y.S. Lincoln (eds.) handbook of Qualitative Research $2^{\text {nd }}$ ed. London: Sage.

[24] Agile Manifesto, http://agilemanifesto.org/principles.html

[25] Racheva, Z., Daneva, M., Sikkel, K., Buglione, L., Business Value Is Not Only Dollars - Results from Case Study Research on Agile Software Projects; PROFES 2010, Springer, pp 131-145

[26] Racheva, Z., Daneva, M., Sikkel, A. Herrmann, R. Wieringa, Do we Know Enough about Requirements Prioritization in Agile Projects: Insights from a Case Study, In Proceedings of RE 2010, Australia, September 2010.

[27] Whitworth E., Biddle R., The Social Nature of Agile Teams, AGILE 2007, IEEE CS.

[28] Bechtel W., A. Abrahamsen, Explanation: a Mechanist Alternative, Journal on Studies in History and Philosophy of Biological and Biomedical Sciences, 36, 2005, 421441. 